\title{
Psychological and behavioral complications in children and adolescents with type 1 diabetes mellitus in Sohag
}

\author{
Saber Hadad ${ }^{1 *} \mathbb{D}$, Magda Mohamed $\mathrm{Ali}^{2}$ and Taher Abdelraheem Sayed ${ }^{1}$
}

\begin{abstract}
Background: Type 1 diabetes mellitus is a chronic disease mainly diagnosed in children and adolescents. It has multiple psychiatric comorbidities. Our aim in this study was to determine the prevalence of psychological and behavioral problems in children and adolescents diagnosed with type 1 diabetes and to find if there is a strong correlation between these problems and different epidemiological- and disease-related factors such as age of the child, duration of diabetes, and other risk factors. We conducted a cross-sectional study and compared between 564 children diagnosed with diabetes mellitus type 1 (who attended Specialized Health Insurance Clinic in Sohag City, Upper Egypt, during the year 2018/2020) and 564 non-diabetic children matched with the diabetic children for age, sex, and socio-economic status. We used "Strengths and Difficulties Questionnaire (SDQ)" to screen for behavioral, social, and emotional problems in diabetic and control children. "SDQ" is a 25-item brief behavioral screening questionnaire that consists of five subscales which are emotional problems, hyperactivity-inattention problems, conduct problems, peer problems, and prosocial behavior subscales. It generates total score and individual score for each subscale.

Results: In our study, we found that diabetic children had significantly higher prevalence of emotional and behavioral problems than control children $(92.37 \%$ of diabetic children versus $20.2 \%$ of control children had abnormal total SDQ score with $\mathrm{P}$ value $<0.001$ ). All subscales of SDQ except prosocial subscale were significantly affected in children with type 1 diabetes mellitus than control children with $P$ value $<0.001$. Certain factors were significantly associated with impaired subscales of SDQ scale. We found a positive correlation between age and emotional, hyperactivity and conduct problems as these problems were more frequent in older children. Female children had more hyperactivity and conduct problems than male children $(68.6 \%, 71.7 \%$ vs. $58.0 \%, 62.0 \%, \mathrm{P} 0.002$ and 0.003 , respectively) while male children were more affected by emotional problems than female children $(68 \%$ vs. 57.4\%, P 0.003). Peer problems were more prevalent in children of parents with higher educational level. Children with positive family history of diabetes were less affected by emotional problems than children with negative family history (50\% vs.64.3\%, P 0.04). Longer duration of disease was associated with increased prevalence of peer and emotional problems. Poor control of diabetes increased the prevalence of conduct and emotional problems (P 0.007 and 0.022, respectively).
\end{abstract}

\footnotetext{
* Correspondence: dr_hadad201444@yahoo.com

${ }^{1}$ Department of Neuropsychiatry, Faculty of Medicine, Sohag University,

Sohag, Egypt

Full list of author information is available at the end of the article
}

\section{Springer Open}

(c) The Author(s). 2021 Open Access This article is licensed under a Creative Commons Attribution 4.0 International License, which permits use, sharing, adaptation, distribution and reproduction in any medium or format, as long as you give appropriate credit to the original author(s) and the source, provide a link to the Creative Commons licence, and indicate if changes were made. The images or other third party material in this article are included in the article's Creative Commons licence, unless indicated otherwise in a credit line to the material. If material is not included in the article's Creative Commons licence and your intended use is not permitted by statutory regulation or exceeds the permitted use, you will need to obtain permission directly from the copyright holder. To view a copy of this licence, visit http://creativecommons.org/licenses/by/4.0/. 
Conclusion: Children with type 1 diabetes mellitus have more emotional, hyperactivity, conduct, and peer problems than non-diabetic children. These findings indicate a need to screen diabetic children and adolescents for behavioral and emotional problems and treat these problems if found.

Keywords: Psychological, Behavioral, Emotional, Type 1 diabetes mellitus, Children, Adolescents

\section{Background}

Diabetes mellitus type 1 is usually diagnosed in children and adolescents [1]. As a chronic disease, patients suffering from diabetes mellitus are at a high risk for psychological, behavioral, and social problems [2]. "The International Society for Paediatric and Adolescent Diabetes (ISPAD) recommends that children and adolescents with type 1 diabetes are screened for psychological problems [3]," but there is no definite accurate guidelines based on evidence to address specific disorders or use specific tools in screening [4]. We reviewed the studies done to investigate the psychological, emotional, and behavioral impact of diabetes mellitus type 1 in children and adolescents, and we found that most of these studies were conducted on limited numbers of patients [5-7]. In our study, we tried to add to the previous work done in this area and tried to include a large representative sample and tried to avoid confounding factors that might affect the accuracy of the results. Also, we tried to found factors correlated with different psychological and behavioral problems like age at diagnosis of diabetes mellitus, duration of the disease, glycemic control, family history of diabetes, and other factors as we will show in results.

\section{Methods}

\section{Study design, setting, and population}

This study is a cross-sectional study conducted on 564 children with type 1 diabetes attending the specialized health insurance clinic in Sohag City, Upper Egypt, during the year 2018/2020.

\section{Inclusion criteria}

Age from 4 to 17 years. At least 6 months from diagnosis of diabetes and on insulin therapy. No complications from diabetes, e.g., diabetic nephropathy or neuropathy. No other major medical illness. No organic brain diseases such as intellectual impairment.

\section{Exclusion criteria}

We excluded patients with diabetic complications, e.g., diabetic nephropathy or neuropathy, patients with other major medical illnesses or organic brain insults.

\section{Sample size and technique}

We calculated the sample size using EPI info program. Using a prevalence rate of diabetes $18 \%$. The calculated sample size was 490 with a drop out $10 \%$ so total are 564 at confidence interval $95 \%$. We selected the patients from diabetic children attending health insurance clinic in Sohag City during the period of the study. Control group consisted of 564 children with no diabetes. We selected the control children from kindergarten schools of the same area of patients group. Both patients and control group were matched regarding age, sex, and family's socioeconomic level.

\section{Data collection tools}

To collect data we used a semi-structured questionnaire that included socio-demographic factors such as age of the child, sex of the child, residence, family income, job and education of the parents, and family history of diabetes. The questionnaire included also variables related to the disease as age of the child at diagnosis, duration since diagnosis, type of insulin used and frequency of use, blood glucose level, and last glycated hemoglobin (HbA1c).

\section{Tool I}

To assess socio-economic level, we used family socioeconomic status scale prepared by Abd El-Twab, 2012) [8]. It includes four items: family income, level of education of parents, job of parents, and lifestyles. It gives total score and separate score for each item. The three classes of the total score are low, moderate, and high.

\section{Tool II}

We used the Strengths and Difficulties Questionnaire (SDQ) to identify the behavioral, social, and emotional problems in diabetic and control children. The Strengths and Difficulties Questionnaire (SDQ) is a brief behavioral screening tool used for children and adolescents. The 25 items in the SDQ comprise 5 subscales of 5 items each. The subscales include (1) emotional symptoms subscale, (2) conduct problems subscale, (3) hyperactivity/inattention subscale, (4) peer relationships problem subscale, and (5) prosocial behavior subscale (Goodman, 1997) [9]. Scoring of SDQ gives separate score for each subscales and gives total score by summation of the first 4 subscales (excluding prosocial subscale). Total score ranges from 0 to 40 , with scores $0-15$ considered normal, 16-19 borderline, and 20-40 abnormal. Each individual subscale has a separate scoring: emotional problems subscale scoring as follows: normal 
from 0 to 5 , borderline from 6 and abnormal from 7 to 10 . Conduct problems subscale scored is interpreted as normal from 0 to 3, borderline 4, and abnormal from 5 to 10 . The hyperactivity-inattention sub-scale is interpreted as normal from 0 to 5 , borderline 6 , and abnormal from 7 to 10. Peer problems sub-scale is interpreted as normal from 0 to 3 , borderline from 4 to 5 , and abnormal from 6 to 10 . The prosocial behavior subscale scores are normal from 6 to 10 , borderline 5 , and abnormal from 0 to 4 [9]. SDQ is widely used, and its validity and reliability are wellestablished in several studies (Goodman 2001, Muris et al. 2003, Obel et al. 2004, Niclasen et al. 2012) [10-13]. In our study, we used the Arabic version of the SDQ (Almaqrami and Shuwail, 2004) [14].

\section{Field work}

We carried out a pilot study on $5 \%$ of the sample. We conducted this pilot study to assess the clarity of the questions and if they need any rewording and to determine the time needed in fulfilling the questionnaire. During this pilot study, the participants needed about 20-25 min to complete the questionnaire. We included data obtained from the pilot study were included in the study group. We interviewed each child individually. One of the researchers was available either in the health insurance clinics for the studied children or in the class room for the control group.

\section{Study period}

We conducted our study from October 2018 to June 2020.

\section{Statistical analysis}

We used SPSS software (version 16) to analyze the data. In descriptive statistics, we presented quantitative data in the form of mean and standard deviation (SD) while qualitative data were presented in the form of frequencies and percentages. We used chi-square test to test the difference between the proportions of variables to compare between diabetic children and control children. To clarify the independent demographic variables and disease-related variables that are associated with psychological and behavioral problems, we used bivariate and multivariate logistic regressions. P value $<0.05$ is considered statistically significant.

\section{Results \\ Sociodemographic data \\ Patients group}

The number was 564 children with age range 4-16 years. The mean age was $12.6 \pm 3.3($ mean \pm SD). Male children were $47.2 \%$ of them.

\section{Control group}

Five hundred sixty-four non-diabetic children with age range $4.5-16$ years. The mean age was $13.2 \pm 3.2$. Male children were $51 \%$ of the sample.

No significant difference between patients and control group regarding age and sex (P 0.48 and 0.37 , respectively) (Fig. 1).

Socioeconomic class of control children; $48 \%$ low, $32 \%$ moderate, and $20 \%$ high. There is no significant difference between patients and control group regarding socioeconomic status (P 0.18).

Table 1 shows Difficulty Index Score in diabetic and control children. $92.37 \%$ of diabetic children $(n=521$ out of 564) had abnormal total score compared to $20.2 \%$ of the control children ( $\mathrm{n}=114$ out of 564). In comparison with control children, diabetic children were significantly affected in all subscales except prosocial subscale (P value $<0.001$ ).

Table 2 is showing the relation between different demographic and disease related variables different subscales of SDQ in diabetic children. Certain factors were significantly associated with impaired subscales of SDQ scale. Regarding age, older children had higher prevalence of emotional, hyperactivity, and conduct problems than younger children. Regarding sex of the child, girls were more affected by hyperactivity and conduct problems than boys $((68.6 \%, 71.7 \%$ vs. $58.0 \%, 62.0 \%)$ and less affected by emotional problems than boys, $57.4 \%$ vs. $68.0 \%$ ). Peer problems were more prevalent in children of parents with higher educational level. Children with positive family history of diabetes experienced less emotional problems. Children with longer duration of diabetes had significantly higher peer and emotional problems. Conduct and emotional problems were significantly higher in children with poor glycemic control (Table 3).

Multivariate logistic analysis shows that age and sex of the diabetic child, the educational level of the mother, duration of diabetes, and family history of diabetes were

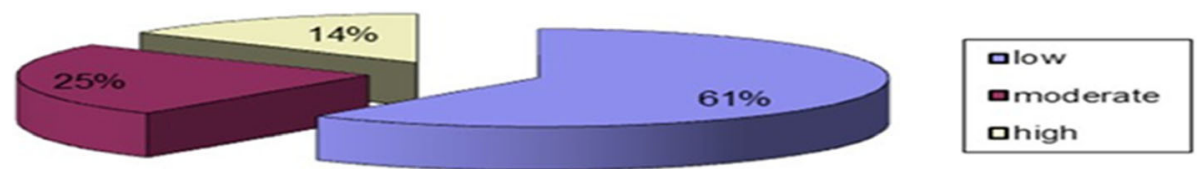

Fig. 1 Socioeconomic level of diabetic children 
Table 1 Difficulty Index Scores of diabetic and control children

\begin{tabular}{|c|c|c|c|c|c|c|c|}
\hline \multicolumn{8}{|c|}{ Difficulty Index Score } \\
\hline \multirow{2}{*}{$\begin{array}{l}\text { Difficulty Index } \\
\text { scoring }\end{array}$} & \multirow{2}{*}{$\begin{array}{l}\text { Children with } \\
\text { diabetes(564) } \\
\text { Normal n (\%) }\end{array}$} & \multirow[b]{2}{*}{$\begin{array}{l}\text { Borderline } \mathrm{n} \\
\text { (\%) }\end{array}$} & \multirow[b]{2}{*}{$\begin{array}{l}\text { Abnormal n } \\
\text { (\%) }\end{array}$} & \multicolumn{2}{|c|}{ Control children(564) } & \multirow[b]{2}{*}{$\begin{array}{l}\text { Abnormal n } \\
\text { (\%) }\end{array}$} & \multirow[b]{2}{*}{$\begin{array}{l}P \\
\text { value }\end{array}$} \\
\hline & & & & $\begin{array}{l}\text { Normal } \mathrm{n} \\
\text { (\%) }\end{array}$ & $\begin{array}{l}\text { Borderline } \mathbf{n} \\
\text { (\%) }\end{array}$ & & \\
\hline Emotional scale & $151(26.77)$ & $60(10.63)$ & $353(62.58)$ & $340(60.28)$ & $91(16.13)$ & 135(23.9) & $<0.001$ \\
\hline $\begin{array}{l}\text { Hyperactivity } \\
\text { scale }\end{array}$ & 137(24.29) & $68(12)$ & $359(63.65)$ & $267(47.34)$ & 185(32.8) & $112(19.85)$ & $<0.001$ \\
\hline Conduct scale & $131(23.22)$ & $55(9.75)$ & $378(67)$ & $371(65.78)$ & $32(5.67)$ & 164(29.0) & $<0.001$ \\
\hline Prosocial scale & 509(90.24) & $27(4.78)$ & $28(4.96)$ & $525(93)$ & $24(4.25)$ & $15(2.65)$ & 0.18 \\
\hline Total score & $17(3)$ & $26(4.6)$ & $521(92.37)$ & $372(65.95)$ & $78(13.8)$ & $114(20.2)$ & $<0.001$ \\
\hline
\end{tabular}

$P$ value $<0.05$ is considered statistically significant. $P$ value $<0.001$ is considered highly significant.

predictors of emotional problems. For hyper-activity and conduct problems, the predictors were age and sex of the child and were predictors of conduct problems and hyperactivity problems. Educational level of father and duration of diabetes in years were predictors of peer relationship problems (Fig. 2).

\section{Discussion}

\section{Principal findings}

In our study, we found that diabetic children had significantly higher prevalence of psychological, behavioral, and social problems than control children $(92.37 \%$ vs. 20.2\%, P 0.001). All subscales of SDQ except prosocial subscale were significantly affected in children with type 1 diabetes mellitus than control children. The higher prevalence of emotional and behavioral problems in diabetic children may be explained by the stress of chronic illness diagnosis and stress of treatment as painful injections and diet and life style restrictions as well as stigma and social stressors from peers and the society as a whole.

Certain factors were significantly associated with impaired subscales of SDQ scale. We found a positive correlation between age and emotional, hyperactivity, and conduct problems as these problems were more frequent in older children. Female children had more hyperactivity and conduct problems than male children $(68.6 \%$, $71.7 \%$ vs. $58.0 \%, 62.0 \%$, P 0.002 and 0.003 , respectively), while male children were more affected by emotional problems than female children $(68 \%$ vs. $57.4 \%, \mathrm{P}$ 0.003).). Peer problems were more prevalent in children of parents with higher educational level. Children with positive family history of diabetes were less affected by emotional problems than children with negative family history (50\% vs.64.3\%, P 0.04). Longer duration of disease was associated with increased prevalence of peer and emotional problems. Poor control of diabetes increased the prevalence of conduct and emotional problems (P 0.007 and 0.022, respectively).

\section{Relation to other studies}

Previous studies which were done to determine the psychological and behavioral complications of diabetes in children and adolescents found that diabetic children had higher prevalence of these problems. Different studies focused on certain psychological problems such as depression, eating problems, and suicide. Most of these studies included small numbers of patients. In our study, we tried to add to the previous work done in this area and tried to include a large representative sample and tried to avoid confounding factors that might affect the accuracy of the results. Also, we tried to find factors correlated with different psychological and behavioral problems like age at diagnosis of diabetes mellitus, duration of the disease, glycemic control, and family history of diabetes. Our results confirm the results in previous studies. Most of these studies were small and investigated specific disorders [57]. Three recent large studies showed similar results Denmark, Sweden, and Australia [15-17].

A large Danish study compared 5084 child and adolescent patients diagnosed with type 1 diabetes mellitus with age- and sex-matched controls regarding diagnosis with one or more psychiatric disorders. The researchers found significant higher incidence of anxiety disorders, depression, eating disorders, somatization disorders, and dissociations in diabetic group [15].

A second large Swedish study followed 17,122 child and adolescent diagnosed with diabetes mellitus type 1 for 5 years. The control subjects $(n=18,847)$ were the healthy siblings of the patients (this was a strength point in this study as patients and controls are to large extent similar in genetics and social factors). The researchers found that the incidence of different psychiatric disorders was twice more common in patients than controls. The main psychiatric disorders diagnosed in patients group were depression, anxiety, eating disorders, inattention, hyperactivity, conduct disorder, and abuse of addictive substances [16].

A third large study from Australia, compared between 1303 patients with type 1 diabetes and 6422 healthy 
Table 2 Factors associated with abnormal SDQ subscales

\begin{tabular}{|c|c|c|c|c|c|}
\hline \multirow[t]{2}{*}{ Variables } & \multirow{2}{*}{$\begin{array}{l}\text { Number } \\
\mathrm{N}=564\end{array}$} & \multicolumn{2}{|l|}{ Difficulty index subscale } & \multirow[b]{2}{*}{ Hyperactivity $\mathrm{n}=359$ (\%) } & \multirow[b]{2}{*}{ Peer $n=464(\%)$} \\
\hline & & Emotional $n=352(\%)$ & Conduct $\mathrm{n}=378(\%)$ & & \\
\hline \multicolumn{6}{|l|}{ Age in years } \\
\hline $4<6$ & $40(7.1)$ & $11(26.7)$ & $12(30.0)$ & $16(40.0)$ & $30(76.7)$ \\
\hline $6<12$ & 219(38.8) & $141(64.6)$ & $144(65.9)$ & $136(62.2)$ & $190(87.2)$ \\
\hline$\geq 12$ & $305(54.0)$ & $200(65.5)$ & $222(72.9)$ & $207(67.7)$ & $244(79.5)$ \\
\hline$P$ value & & 0.000 & 0.000 & 0.01 & 0.10 \\
\hline \multicolumn{6}{|l|}{ Sex of the child } \\
\hline Male & $267(47.3)$ & $182(68.0)$ & $166(62.0)$ & $155(58.0)$ & $216(81.0)$ \\
\hline Female & $297(52.7)$ & $170(57.4)$ & $213(71.7)$ & $204(68.6)$ & $248(83.4)$ \\
\hline$P$ value & & 0.03 & 0.03 & 0.02 & 0.52 \\
\hline \multicolumn{6}{|l|}{ Birth order } \\
\hline First & $100(17.7)$ & $67(66.7)$ & $76(76.0)$ & $73(73.3)$ & $82(82.7)$ \\
\hline Second & $144(25.5)$ & $89(62.0)$ & $89(62.0)$ & $92(63.9)$ & $123(85.2)$ \\
\hline Third & $320(56.7)$ & $196(61.2)$ & $213(66.7)$ & $194(60.4)$ & $259(80.8)$ \\
\hline$P$ value & & 0.697 & 0.138 & 0.127 & 0.614 \\
\hline \multicolumn{6}{|c|}{ Education of child's mother } \\
\hline Illiterate & $221(39.2)$ & $124(56.0)$ & $137(62.0)$ & $13(59.0)$ & $167(75.9)$ \\
\hline$<12$ years & 109(19.3) & $85(78.0)$ & $85(78.0)$ & $80(73.2)$ & $90(82.9)$ \\
\hline$\geq 12$ years & 234(41.4) & $143(61.1)$ & $157(66.9)$ & $149(63.4)$ & $207(88.0)$ \\
\hline$P$ value & & 0.003 & 0.041 & 0.093 & 0.014 \\
\hline \multicolumn{6}{|c|}{ Education of child's father } \\
\hline Illiterate & $142(25.1)$ & $76(53.8)$ & $90(63.2)$ & $90(63.2)$ & $100(70.8)$ \\
\hline$<12$ years & 111(19.6) & $74(66.3)$ & $83(74.7)$ & $72(65.1)$ & $90(81.9)$ \\
\hline$\geq 12$ years & $312(55.3)$ & $203(65.0)$ & $207(66.2)$ & $197(63.2)$ & $274(87.6)$ \\
\hline$P$ value & & 0.103 & 0.226 & 0.953 & 0.001 \\
\hline \multicolumn{6}{|c|}{ Family history of diabetes } \\
\hline Yes & $74(13.2)$ & $37(50.0)$ & $53(71.4)$ & $48(64.3)$ & $64(87.5)$ \\
\hline No & $490(86.8)$ & $315(64.3)$ & $326(66.5)$ & $311(63.5)$ & $400(81.5)$ \\
\hline$P$ value & & 0.040 & 0.463 & 0.908 & 0.271 \\
\hline \multicolumn{6}{|c|}{ Duration of diabetes in years } \\
\hline$<1$ year & $72(12.8)$ & 25(35.2) & $43(59.3)$ & $43(59.3)$ & $59(83.3)$ \\
\hline 1 to $<3$ years & $143(25.3)$ & $91(63.6)$ & $88(61.2)$ & $87(60.7)$ & 101(71.0) \\
\hline 3 to $<5$ years & 188(33.3) & $128(68.1)$ & 155(82.4) & $117(62.4)$ & $160(85.1)$ \\
\hline$\geq 5$ years & 161(28.6) & 108(66.9) & $120(74.6)$ & $112(69.4)$ & $144(88.4)$ \\
\hline P value & & 0.000 & 0.367 & 0.445 & 0.004 \\
\hline \multicolumn{6}{|l|}{ Glycemic control } \\
\hline Controlled & 209(37.1) & $145(69.4)$ & $157(75.2)$ & $144(68.8)$ & $167(80.3)$ \\
\hline Uncontrolled & $355(62.9)$ & $207(58.3)$ & $221(62.4)$ & $215(60.5)$ & 297 (83.5) \\
\hline$P$ value & & 0.022 & 0.007 & 0.088 & 0.405 \\
\hline
\end{tabular}

$\mathrm{P}$ value $<0.05$ is considered statistically significant. $\mathrm{P}$ value $<0.001$ is considered highly significant 
Table 3 Determinants of abnormal SDQ Subscales by logistic regression

\begin{tabular}{|c|c|c|c|c|}
\hline Subscale & Significant variables & Significant independent & OR & $P$ value \\
\hline \multirow[t]{5}{*}{ Emotional } & Duration of diabetes & $\geq 5$ years & 3.2 & 0.004 \\
\hline & Child age & Older child & 5.1 & 0.001 \\
\hline & Child gender & Female & 0.6 & 0.012 \\
\hline & Family history diabetes & No & 2.1 & 0.015 \\
\hline & Mother education & High & 0.5 & 0.04 \\
\hline \multirow[t]{2}{*}{ Conduct } & Child age & Older child & 5.4 & 0.001 \\
\hline & Child gender & Female & 1.6 & 0.03 \\
\hline \multirow[t]{2}{*}{ Hyperactivity } & Child age & Older child & 2.8 & 0.02 \\
\hline & Child gender & Female & 1.7 & 0.02 \\
\hline \multirow[t]{2}{*}{ peer } & Duration of diabetes & $\geq 5$ years & 3.2 & 0.002 \\
\hline & Father education & High & 2.5 & 0.009 \\
\hline
\end{tabular}

OR odds ratio, $\mathrm{Cl}$ confidence interval $=95 \%$

individuals matched with the patients group for age and sex. The researchers found that $14.3 \%$ of patients groups were diagnosed with ant psychiatric disorder, while in control subjects, only $6.2 \%$ were diagnosed with a psychiatric disorder. The main psychological problems diagnosed in patients group were depression, anxiety, eating disorders, and conduct disorders. Poor control of diabetes was significantly associated with diagnosis of different psychiatric disorders [17].

\section{Factors associated with different psychiatric problems}

In our study, we tried to address certain factors that may be associated with different psychological and behavioral problems. We selected certain factors which were significant in previous studies and added other risk factors that we speculated may be associated with psychological problems.

\section{Age at diagnosis of type 1 diabetes mellitus}

In our study, we found a positive correlation between age and emotional, hyperactivity, and conduct problems as these problems were more frequent in older children. The Danish study found that the highest risk for diagnosis with any psychiatric disorder occurred when diabetes was first diagnosed between 10 and 14 years of age [15]. This finding was also noticed in the Swedish study as the researchers found an increasing incidence of psychological problems when diabetes was first diagnosed in older children [16]. A suggested, explanation of these findings is that pre-adolescence and adolescence are naturally sensitive periods of development, combined with the stress of diagnosis of diabetes mellitus and the possible social and emotional strains commonly occurring in this age group [18]. Our explanation to this relation may be that as the child is older his perception of the disease and social stressors is increased and also the duration of the illness and suffering from it is mostly longer as the child is older.

\section{Sex of the patients}

In our study, we found that female children had more hyperactivity and conduct problems than male children $(68.6 \%, 71.7 \%$ vs. $58.0 \%, 62.0 \%)$ while male children were more affected by emotional problems than female children (68\% vs.57.4\%). The Danish study found that abuse of psychoactive substances was significantly higher in male patients, while personality changes were higher among female patients. The Australian and Swedish studies did not stratify patients based on sex [15-17]. We did not find an explanation to this finding, as what is well known is that conduct problems and hyperactivity problems are higher in males than in females, while emotional problems are more frequent among females. Our results were opposite to that.

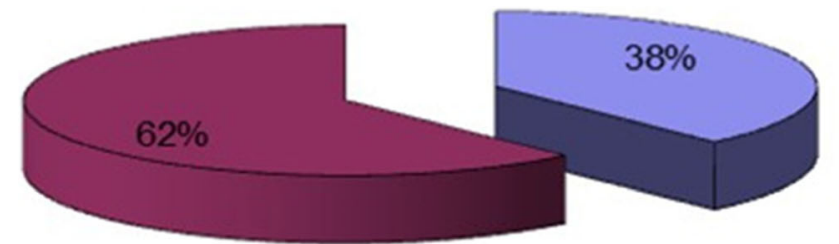

acontrolled

auncontrolled

Fig. 2 Glycemic control in diabetic children 


\section{Other factors associated with psychological and behavioral problems}

Some other factors are found to be associated with certain problems in diabetic children. Peer problems were more frequent in children of parents with higher educational level. Children with positive family history of diabetes were less affected by emotional problems than children with negative family history $(50 \%$ vs. $64.3 \%$, P 0.04 ); this may be explained by the experience of the family about the disease and its management. Longer duration of disease was associated with increased prevalence of peer and emotional problems. Poor control of diabetes increased the prevalence of conduct and emotional problems, and this may be explained by the biological effects of hyperglycemia on mood and behavior and also the stress of management of the complications of poor glycemic control which add to the stress of management of the disease itself.

\section{Limitations of the study}

We recommend the use of more accurate and specific questionnaires for screening and diagnosis of different psychiatric disorders in the following studies.

\section{Conclusions}

In this study, we confirmed the previously noticed results that a number of behavioral, emotional, and social problems commonly occur in children and adolescents with diabetes mellitus type 1 . More studies are needed to define accurate tools for diagnosis of specific disorders and also to determine the benefits of early detection and proper management of these psychiatric disorders. Also, there is a need for more collaboration between child and adolescent psychiatrists and pediatricians to improve the quality of life of these children and adolescents.

\section{Abbreviations \\ ISPAD: International Society for Paediatric and Adolescent Diabetes; SDQ: Strengths and Difficulties Questionnaire}

\section{Acknowledgements}

We are expressing our cordial gratitude to the appreciated effort and time given by all patients, their parents, and the control group participants.

\section{Declarations}

\section{Authors' contributions}

S.H.: contribution in research idea selection, applying the questionnaires, paper writing, revising the references, and paper submission. M. M.A: contribution in research idea selection, sampling planning, and supervising the field work. T. A. S.: recruiting and interviewing the patients, applying the questionnaires, and sample collection. All authors have read and approved the final manuscript.

\section{Funding}

The authors of this manuscript declare that no funding bodies were involved in sponsoring or funding this research.

\section{Availability of data and materials}

The datasets used and/or analyzed during the current study are available from the corresponding author on reasonable request.

\section{Ethics approval and consent to participate}

The study protocol was approved by the Medical Research Ethics Committee of Faculty of Medicine, Sohag University. An official permission was obtained from director of Health Insurance Institute for Upper Egypt for the studied children. Central Agency for Public Mobilization and Statistics (CAPMAS), Issue number 771 and Ministry of Education, Sohag Governorate, for collecting data for the control children. Informed consent was obtained from the caregivers of the children participating in the study. The researchers assured voluntary participation and confidentiality of each child who agrees to participate in this study.

\section{Consent for publication}

Consent for publication was obtained.

\section{Competing interests}

All authors declare that they have no competing interests.

\section{Author details}

'Department of Neuropsychiatry, Faculty of Medicine, Sohag University, Sohag, Egypt. ${ }^{2}$ Department of Public Health and Community Medicine, Sohag Faculty of Medicine, Sohag, Egypt.

Received: 28 April 2021 Accepted: 14 June 2021

Published online: 02 August 2021

References

1. Maahs DM, West NA, Lawrence JM (2010) Mayer-Davis EJ (2010). Epidemiology of type 1 diabetes. Endocrinol Metab Clin N Am 39(3):481497. https://doi.org/10.1016/j.ecl.2010.05.011

2. Cox DJ, Gonder-Frederick L (1992) Major developments in behavioral diabetes research. J Consult Clin Psychol 60(4):628-638. https://doi.org/10.1 037/0022-006X.60.4.628

3. Delamater AM, de Wit M, McDarby V, Malik J, Acerini CL (2014) ISPAD clinical practice consensus guidelines 2014. Psychological care of children and adolescents with type 1 diabetes. Pediatr Diabetes 15(Suppl20):232244. https://doi.org/10.1111/pedi.12191

4. Jensen PS, Goldman E, Offord D, Costello EJ, Friedman R, Huff B, Crowe M, Amsel L, Bennett K, Bird H, Conger R, Fisher P, Hoagwood K, Kessler RC, Roberts R (2011) Overlooked and underserved: "action signs" for identifying children with unmet mental health needs. Pediatrics 128(5):970-979. https:// doi.org/10.1542/peds.2009-0367

5. Reynolds KA, Helgeson VS (2011) Children with diabetes compared to peers: depressed? Distressed? A meta-analytic review. Ann Behav Med 42(1):29-41. https://doi.org/10.1007/s12160-011-9262-4

6. Buchberger B, Huppertz H, Krabbe L, Lux B, Mattivi JT, Siafarikas A (2016) Symptoms of depression and anxiety in youth with type 1 diabetes: a systematic review and meta-analysis. Psychoneuroendocrinology 70:70-84. https://doi.org/10.1016/j.psyneuen.2016.04.019

7. Johnson B, Eiser C, Young V, Brierley S, Heller S (2013) Prevalence of depression among young people with Type 1 diabetes: a systematic review. Diabet Med 30(2):199-208. https://doi.org/10.1111/j.1464-5491.2012.03721.x

8. Abd El-Tawab AA (2012) Family socio-economic status scale. J Faculty Educ Assiut Univ 28(1)

9. Goodman R (1997) The Strengths and Difficulties Questionnaire: a re-search note. J Child Psychol Psychiatry 38:581-586. Available at:. https://doi.org/1 $0.1111 /$ j.1469-7610.1997.tb01545.x

10. Goodman R (2001) Psychometric properties of the strengths and difficulties questionnaire (2001). J Am Acad Child Adolesc Psychiatry 40(11):1337-1345. https://doi.org/10.1097/00004583-200111000-00015

11. Muris P, Meesters C, van den Berg F (2003) The Strengths and Difficulties Questionnaire (SDQ)--further evidence for its reliability and validity in a community sample of Dutch children and adolescents. Eur Child Adolesc Psychiatry 12(1):1-8. https://doi.org/10.1007/s00787-003-0298-2

12. Obel C, Heiervang E, Rodriguez A, Heyerdahl S, Smedje H, Sourander A, Guethmundsson OO, Clench-Aas J, Christensen E, Heian F, Mathiesen KS, Magnússon P, Njarethvík U, Koskelainen M, Rønning JA, Stormark KM, Olsen J (2004) The Strengths and Difficulties Questionnaire in the Nordic 
countries. Eur Child Adolesc Psychiatry 13(Suppl 2):I32-II39. https://doi.org/1 0.1007/s00787-004-2006-2

13. Niclasen J, Teasdale TW, Andersen AM, Skovgaard AM, Elberling H, Obel C (2012) Psychometric properties of the Danish Strength and Difficulties Questionnaire: the SDQ assessed for more than 70,000 raters in four different cohorts. PLoS One 7(2):e32025. https://doi.org/10.1371/journal. pone.0032025 Epub 2012 Feb 27

14. Almaqrami M, Shuwail A (2004) Validity of the Self-report Version of the Strengths and Difficulties Questionnaire in Yemen. Saudi Med J 25(5):592601

15. Dybdal D, Tolstrup JS, Sildorf SM, Boisen KA, Svensson J, Skovgaard AM et al (2018) Increasing risk of psychiatric morbidity after childhood onset type 1 diabetes: a population-based cohort study. Diabetologia 61:831-838

16. Butwicka A, Frisen L, Almqvist C, Zethelius B, Lichtenstein P (2015) Risks of psychiatric disorders and suicide attempts in children and adolescents with type 1 diabetes: a population-based cohort study. Diabetes Care 38(3):453459. https://doi.org/10.2337/dc14-0262

17. Cooper MN, Lin A, Alvares GA, de Klerk NH, Jones TW, Davis EA (2017) Psychiatric disorders during early adulthood in those with childhood onset type 1 diabetes: rates and clinical risk factors from population-based followup. Pediatr Diabetes 18(7):599-606. https://doi.org/10.1111/pedi.12469

18. Costello EJ, Egger H, Angold A (2005) 10-year research update review: the epidemiology of child and adolescent psychiatric disorders: Methods and public health burden. J Am Acad Child Adolesc Psychiatry 44(10):972-986. https://doi.org/10.1097/01.chi.0000172552.41596.6f

\section{Publisher's Note}

Springer Nature remains neutral with regard to jurisdictional claims in published maps and institutional affiliations.

\section{Submit your manuscript to a SpringerOpen ${ }^{\circ}$ journal and benefit from:}

- Convenient online submission

- Rigorous peer review

- Open access: articles freely available online

- High visibility within the field

- Retaining the copyright to your article

Submit your next manuscript at $\boldsymbol{\nabla}$ springeropen.com 